\title{
"Bits and Pieces" to Improve the Students' Writing Skill: Using Educational Game as an Approach to Teach Descriptive Text
}

\author{
Ramanda Rizky \\ Padang State University, Padang, Indonesia \\ ramandarizky0@gmail.com
}

\section{ARTICLE HISTORY \\ Received : 12 February 2020 \\ Revised : 23 February 2020 \\ Accepted : 23 February 2020}

\section{KEYWORDS}

\section{Writing Skill}

Descriptive Text

Educational Game

Classroom Action Research (CAR)

English as a Foreign Language (EFL)

\begin{abstract}
Students in Indonesia who learn English as a Foreign Language (EFL) encounter problems in learning how to write in English. Not a novel problem in the least, but the more connected the world is becoming due to the availability of information and communication technologies (ICT). This study aims to address the need to improve the generation's English skills, lest they are left behind the moving era. This study is a classroom action research (CAR), using a test, observation, field note, and interviews as the research instruments. Twenty-nine middle school students were taught to produce descriptive texts using the approach of an educational game called Bits and Pieces. The results showed that the game improved students' average scores in writing descriptive text from 70.12 (cycle I) to 79.75 (cycle II) as students' were unanimously interested in the strategy, much more so than traditional approaches.
\end{abstract}

\section{Introduction}

Learning English involves the mastery of four language skills; they are listening, speaking, reading and writing (Herlinawati, 2011). Speaking and writing are productive skills or ability to produce language, listening and reading are receptive skill or ability to comprehend information (Syafitri, Budiarti, \& Derin, 2019). The fourth basic skills are taught in an integrative way, and extensive research has been conducted individually, collaboratively, and longitudinally to address such matters (Derin \& Hamuddin, 2019). Writing is a process to produce language (Derin et al., 2019). We can take more time to think and choose words to express our ideas, thought and feeling, and then we revise if it is not clear to express what we intend to write It also needs attention because it needs its principles and the method it requiring mastery not only of grammatical, rhetorical devices but also of the conceptual and judgment (Yunira et al., 2019). For that reason, it needs the practice to improve that skill. In advance, it is a physiological activity of the language used to put information in the written text. Writing is an activity to create records or information on a medium by using a script (Herlinawati, 2014). Writing is usually done on paper by using tools such as a pen or pencil, but nowadays it is highly encouraged to write online because the productions can be published on the Internet and instantly shared with others (Hamuddin, Kurniawan, Syaifullah, \& Herdi, 2018; Wu et al., 2011).

In KTSP as a standard of the education system, students learn writing in term of text types like descriptive, narrative, recount, report, procedure, and anecdote. One of the texts that must be mastered by the students is descriptive text.
The descriptive text describes a particular person or thing in detail. It means that descriptive text is a text describing the features and characteristics of a certain object in detail (a person or a thing).

However, based on an interview with an English Teacher at SMPN 1 Tambusai, it was found students have many problems in writing skill (Hamuddin et al., 2019), especially in descriptive text. The first problem is language features in writing descriptive text (Budiarti, Syafitri, \& Derin, 2019). As we know, the descriptive text uses simple present tense as the language feature. The students had some errors in using the simple present tense. The students made some mistakes when they elaborated the idea in simple present. It made students difficult to write a descriptive text. If they had ideas, they cannot express their ideas in a good sentence and form it into a good paragraph or correct patterns.

The second problem is the preparation of content, which uses descriptive text. The descriptive text should contain detailed information, but most of the students' texts contained less than what is needed to describe something to a regular reader not-in-the-know. The third problem is the students' low mastery of vocabulary (Andriani, 2016). Some of the obstacles in understanding English texts are the poor mastery of vocabulary. It caused them to be unable or less able to construct and organise ideas. The fourth problem is the fact that the method used is not running as it should. There is some strategies strategy in teaching descriptive text might be applied, but teachers would never know what strategy matches with the various condition of students. No strategy can be applied in whole conditions, 
and in this case, the teachers are responsible for finding the correct strategy which can be applied well based on the conditions of the students (Marwa, 2014).

Due to the problems above, the researcher gave a solution in choosing. The researcher chose bits and pieces game as the method to solve students' problem in writing descriptive text. Bits and pieces game is a kind of game with a picture-strip story. It is suitable for narrating events and describing person, place or something, principally in the present tense. The method can be used to solve students problems during the writing process, but the researcher used the technique in making the learning process become structurally and effectively in each step of the writing itself.

\section{Literature Review}

Game is an activity given to the students to use the language in a less formal situation is organised activity that usually has some properties, such as a particular task or objective, a set of rule, competition between players and communication between players by spoken or written language. Besides, the game is one of the media that can be applied in language teaching and learning. All people are like games either young up to adult. But different age is group requires various topic material, competence, and model of the game. For example, while children like a fun game, adults prefer either a relaxing or challenging game. So, a teacher has to choose the appropriate game for all students to be fun learning and active class.

\subsection{Bits and Pieces Game}

Bits and pieces game is a kind of game with a picturestrip story. It is suitable for narrating events and describing person, place or something, principally in the present tense. This game is appropriate to listening, speaking and writing skills. All students can play this game. To play this game we spend 15-40 minutes only, the material that we need is picture-strip stories or texts. On top of the flexible time needed for this game, bits and pieces game makes a great visual aid for students of all ages in general (Gistituati, Refnaldi, \& Syaifullah (2019).

There are many aspects to be considered in playing this game. Those are instruction to the students and the identification of the winner. These are the following steps in teaching descriptive texts using bits and pieces game are; first, teacher divides students into four groups, second, the teacher distributes to every group, one stripping pictures and many papers to the striping pictures to be good picture in 10 minutes, After the striping picture have been arranged, the teacher gives 20 minutes for every group to describe it and write it in a pieces of paper. Then he asks every group to stick the arranging picture on the board and the writing under it. Then he checks what they have done, and tells them the winner of this game based on arranging picture and detailed describing of their writing.
Yang (2001) seems to be the first study to have mentioned on the idea of bits and pieces of information in the context of language learning. This type of approach encourages learners to "locate, retrieve, and comprehend the level of material" that they discover from any sources. Readers read information in scattered bits and pieces not in a textual whole (Tseng, 2008). The best part is the learners' joyful engagement as the bits and pieces of information they receive is stimulating and fascinating. Kinesthetic learners, in particular, "has both the power of breaking down the language into bits and pieces and putting those pieces back together in a big picture style" (Maggioli, 1996).

Bits and pieces approach to teaching English is also proven and advocated by Piasecka (2014). The study recommended using authentic literary texts in a jigsaw reading format to encourage independent language learning and use. The way the researcher did it is by making students read their bits aloud in a way where everyone must pay attention to the text elements so they can put everything into a bigger picture that makes sense. This study is the other related study on the idea of bits and pieces approach as a way to improve English skills of students, and it is the most recent. Therefore, this current study contributes to the scarce literature on the matter and to the field of educational games in EFL context by extension.

Overall, bits and pieces game is a flexible method to be used in teaching, but there is still incomplete knowledge about the use of this game in the actual teaching process. The game would be a suitable candidate for such research projects. For this study, this game is suitable because of the nature of the descriptive text.

\subsection{Descriptive Text}

Descriptive text is one kind of genre in which the teaching process is concerned with what the students do in writing. In teaching descriptive text, the teacher has to give a clear and lively description depends on a close object. Here, the researcher used bits and pieces game which provide many stripping pictures for many students in a group to get clear and details information about the object (picture)

According to Ahmad (2018), there are two models of description; first, a description of a scene which allows the reader to see hears, or even feels the subject matter. Second, spatial order or spatial organisation, usually this organisation involves presenting an overall visual picture of the scene, then locating the specific details in a consistent pattern. The best way to make good description is to describe the area; a pretty, unusual, or lively place and if it's relevant, include some description of typical activity occurring there. Bits and pieces game is one method which is effective to be used in foreign language learning, especially in teaching writing. It is important for the teacher to be creative and innovative. 
The researcher makes this game in a group. These groups involve five students because the students provoke greater involvement and participation than larger groups. They are small enough for real interpersonal interaction, yet not so small that members are over-reliant upon each individual.

Group work such as bits and pieces game can be applied in the classroom because of many advantages; first, like pair work, it dramatically increases the amount of talking for individual students. Second, unlike pair work, because there are more than two people in the group, personal relationships are usually less problematic; there is also a greater chance of different opinions and varied contributions than pair work. Third, it encourages a broader range of skills of cooperation and negotiation than pair work, and yet is more private than working in front of the whole class. Then, it also promotes learner autonomy by allowing students to make decisions in the group without being told what to do by the teacher. Last, although we do not wish any individuals in groups to be completely passive nevertheless some students can choose their level of participation more readily than in a whole class or pair work situation. Although group work has many advantages, it has many disadvantages too. The disadvantages of group work include; it is likely to be noisy (though not necessarily as a loud as pair work can be). Some teachers feel that they lose control, and then not all students enjoy it since they would prefer to be the focus of the teacher's attention rather than working with their peers. Individuals may fall into group roles that become fossilised so that some are passive, whereas others may dominate, the group also take longer to organise than pairs. In this case, the researcher uses bits and pieces as a medium that mitigates these issues.

\section{Method}

This research was a Classroom Action Research. The researcher has conducted the research collaboratively with an English teacher to solve the problem of the students' writing descriptive by applying Bits and Pieces Game at the VIII 6 Grade of SMPN 1 Tambusai. The participants of this research were the students' grade VIII of SMPN 1 Tambusai, and the researcher took VIII 6 Class that consists of 29 students. The researcher chooses the class because of the students at VIII 6 class has a problem in writing descriptive text.

The research was conducted at SMPN 1 Tambusai at Jl. Tuanku Tambusai, Dalu-Dalu. The research was conducted in March 2017. The researcher conducted the research collaboratively with an English teacher to solve the problem of the students' writing descriptive text by applying Bits and Pieces Game at the VIII 6 Grade of SMPN 1 Tambusai.

Action research is any systematic inquiry conduct by those with a direct, vested interest in the teaching and learning process in a particular setting; it is a truly systematic inquiry into one's practice. It is a process that allows teachers to study their classroom to understand them better and to be able to improve their quality or effectiveness (Mertler, 2012). According to Kunandar (2008), action research is an activity undertaken by educators or together with others in collaboration. It aims to enhance or improve the quality of the learning process in the classroom. There are several common features to characterise action research include how it improves education by changing it and learning from the consequences, involve all participants and elements in the classroom, and self-reflects by detailed observation.

This study will use four instruments. The test is one of the methods to collect information from the participant. Firstly, the researcher gave the students a topic about the descriptive text. The students asked to write an essay of descriptive text by concerning its purpose, generic structure and its grammatical features individually. The observation was used to collect the qualitative data done by a collaborator. The collaborator observed the teachers' activities and students' activities in the classroom, and it needs an observation checklist. Also, the researcher and collaborator discussed our finding to conduct improvement for next meeting. And it took two observation checklist for each meeting. The researcher also used an interview to ask the students about their problem in writing descriptive text and how impression after applying Bits and Pieces Game in teaching writing. Lastly, field note was one of qualitative data's instrument used by the researcher to know the improvement while using the strategy and also get some information when the research was conducted.

The data that will be analysed in this classroom action research will be both quantitative and qualitative. In collecting quantitative data, the researcher used the test to earn the data concerned to the students in vocabulary. In collecting quantitative data, the researcher got it from observation, field note and interview. Firstly, the collaborator and the researcher worked together in the teaching and learning process in each meeting to know that learning process run as well or vice versa. As the further, the collaborator also collected the data from field note which as noted in each meeting. In the last, the students were interviewed by asking some questions.

\section{Results \& Discussion}

Based on the purpose of the research, this classroom action research was conducted to find out whether the students' writing skill can be better improved by using Bits and Pieces Game strategy. This research was applied at the second of SMPN 1 Tambusai 2016-2017. This research was conducted in two cycles which contained eight meetings, including test. There were four steps for each cycle, such as plan, action, observation, and reflection. The number of students was 29 students.

Before conducting the research, the researcher had given a preliminary quiz to the students. It was only aimed to get the based data or score about the students' writing 
skill and the ways the students in learning writing. From the quiz results, it was summarised that most of the students had problems in writing a text. The students mostly got $\mathrm{C}$, or the average of their score category was bad. Furthermore, the result of the students' based score can be seen in Table 4.1.

Table 4.1 Scores of Students' Descriptive Text

\begin{tabular}{ccc}
\hline Score Type & Average Score & Percentage \\
\hline Based Score & 46.07 & $10.34 \%$ \\
Cycle I & 70.12 & $37.93 \%$ \\
Cycle II & 79.75 & $72.41 \%$ \\
\hline
\end{tabular}

This research was conducted in two cycles. Each cycle had four meetings that include the test. It had been done since March, $16^{\text {th }} 2017$ until April, 13 ${ }^{\text {th }} 2017$. The research was conducted in SMPN 1 Tambusai at the VIII 6 class in academic years 2016/2017. The number of students was 29 students.

The class was chosen because based on the collaborator suggestion. And it had gotten by the collaborator experiences when teaching English subject in the class. The fact, they had some problems with writing descriptive text. Therefore, the researcher taught the students by using Bits and Pieces Game Strategy on descriptive text.

Based on the data in cycle I, the researcher found that there was no significant improvement by students according to the instruments. Based on the test, the average score is based score was 10.34 and cycle I was 37.93 with increasing point 27.59. Most of the students were failed at this cycle, and the researcher and collaborator try to figure out what problem actually happened in the learning process. Based on the interview, the researcher found there was no improvement because a few things. First of all, the students got no idea with their task and also the strategy ran; it happened because this strategy was never applied at this class before or even by the teacher. That is why the researcher needs to give a brief explanation to students about the aim of this strategy and what rules used at this strategy.

Secondly, comfort situation along the learning process was not created in the class. It caused by un maximum class management where students did not focus when teacher delivering the materials, and because this strategy held in a group exactly it needs well managed to deliver the aim of this strategy to the students.

However, based on the data in cycle II the researcher found clear significant improvement by students according to the instruments of the test. Based on the test, the average score is based score was 10.34 and cycle II was 72.41 , with increasing point 62.07 . Then based on the interview, the researcher found that there was an improvement; because of the students more active in discussion, they could pour a good idea on to their writing task given, and they knew well how to run the strategy according to the rules excellently. Finally, comfort situation in the class along learning process was held; such as better class management, well adaptation by students, and better understanding by students to the strategy so its made the aim of this strategy was reached.

Bits and Pieces can improve the students' writing skill in descriptive text and helped students to solve their difficulties. It supports the students' achievement in each cycle, such as test, observations, field notes, and interviews. Bits and pieces game is one method which is effective to be used in foreign language learning, especially in teaching writing. The teacher needs to be creative and innovative. The researcher makes this game in a group. These groups involve five students because the students provoke greater involvement and participation.than larger groups. They are small enough for real interpersonal interaction, yet not so small that members are over-reliant upon each individual. Group work can be applied in the classroom because of many advantages; first, like pair work, it dramatically increases the amount of talking for individual students. Second, unlike pair work, because there are more than two people in the group, personal relationships are usually less problematic; there is also a greater chance of different opinions and varied contributions than pair work.

Third, it encourages a broader set of skills of cooperation and negotiation than pair work, and yet is more private than work in front of the whole class. It also promotes learner autonomy by allowing students to make decisions in the group without being told what to do by the teacher. Last, although we do not wish any individuals in groups to be completely passive, nevertheless some students can choose their level of participation more readily than in a whole class or pair work situation.

Although group work has many advantages, it has many disadvantages too. The disadvantages of group work include; it is likely to be noisy (though not necessarily as a loud as pair work can be). Some teachers feel that they lose control, and then not all students enjoy it since they would prefer to be the focus of the teacher's attention rather than working with their peers. Individuals may fall into group roles that become fossilised so that some are passive, whereas others may dominate, the group also takes longer to organise than pairs. There are multiple aspects to be considered in playing this game; those are instruction to the students and the identification of the winner. These are the following steps in teaching descriptive texts using bits and pieces game are; first, teacher divides students into four groups second, the teacher distributes to every group, one stripping pictures and many papers to apply Bits and Pieces Game in learning process was not the firstly done, but some previous researches investigate in contribution in teachinglearning process. The results indicated an increase in the number of response parts written and increased stability in the number of words written. 


\section{Conclusion}

After conducting this Classroom Action Research in Improving writing the descriptive text of the class VIII 6 SMPN 1 Tambusai by using Bits and Pieces Game Strategy, according to data in cycle I, the researcher find there is no significant improvement by students according to the instruments. Based on the test, the average score is the based score is 10.34 and cycle I is 37.93 with increasing point 27.59. In cycle II there is a significant improvement by students, the average of students' writing score in based score was 10.34 and cycle II was 72.41, with increasing point 62.07 .

Based on the results, the researcher concluded it is true that using Bits and Pieces Game was able to give significant improvement to students' writing skill in the descriptive text at the Eight 6 Grade of SMPN 1 Tambusai; according to students' achievements in the test that shown significant improvement at the end of cycle II. But, it cannot be denied or covered, especially in the form of improving students' vocabulary and mechanics in writing descriptive text, it showed from students' score for each indicator. They were good at generating ideas such as content, organisation, and grammar; but they were low in vocabulary and mechanics. It showed that they had a low score at the end of cycle II.

Furthermore, this study found that two likely factors influenced the changing of students' writing skill, which are repetition and seriousness aspects of Bits and Pieces. On the former, the students understand about writing skill if they always review the material, and the teacher gives more explanation, information, and material about it. Whereas on the latter, being consistently guided by the teachers to engage in Bits and Pieces means the students aren't distracted to do things outside of the learning context.

\section{Acknowledgement}

The researcher acknowledges and also gives thanks to the colleagues from Unilak-Research Advancement for Intellectual and Scientific Empowerment (U-RAISE) Academy, Applied Linguistics Center, as well as LPPM Unilak for their support during the discussions.

\section{References}

Ahmad, I. (2018). The Implementation of Genre-Based Approach in Improving Students' Descriptive Writing Ability through Sidney Sheldon's Novel Rage of Angels as Role Models. KnE Social Sciences, 372-382.

Andriani, R. (2016). Improving Students' Vocabulary Mastery using Interactive Multimedia. ELTLectura, 3(1).

Budiarti, V., Syafitri, Y. D. T., \& Derin, T. (2019). An Article Review on "Reading Comprehension Strategy Instruction in a First-Year Course: An
Instructor's Self-Study”. ELSYA: Journal of English Language Studies, 1(1), 17-21.

Derin, T., \& Hamuddin, B. (2019). Foreign Language Classroom Anxiety, and Enjoyment During Study Abroad: A Review of Selected Paper. Lisan: Jurnal Bahasa dan Linguistik, 8(2), 76-82.

Derin, T., Deliani, S., Fauziah, N., Afifah, N., \& Hamuddin, B. (2019). Indonesians' Tendency to Refer Abbreviation as Acronym: Types of Abbreviation as Word Formation Process. Globish: An EnglishIndonesian Journal for English, Education, and Culture, 8(2).

Gistituati, N., Refnaldi, R., \& Syaifullah, S. (2019, January). Using Visual Aids to Develop Students' Speaking Skill. In 1st International Conference on Innovation in Education (ICoIE 2018). Atlantis Press.

Hamuddin, B., Kurniawan, K., Syaifullah, S., \& Herdi, H. (2018). Detecting Major Problems in Learning English Through Blog-based Class. Journal of Education and Learning, 12(3), 529-537.

Hamuddin, B., Syahdan, S., Rahman, F., Rianita, D., \& Derin, T. (2019). Do They Truly Intend to Harm Their Friends?: The Motives Beyond Cyberbullying among University Students. International Journal of Cyber Behavior, Psychology and Learning (IJCBPL), 9(4), 32-44.

Herlinawati. (2011). The effectiveness of Indonesian English teachers training programs in improving confidence and motivation. International Journal of Instruction, 4(1).

Herlinawati. (2014). Feedback in English Writing for Indonesian EFL Students. ELT-Lectura, 1(1).

Kunandar, G. P. I. K. T. (2007). Satuan Pendidikan (KTSP) dan Persiapan Menghadapi Sertifikasi Guru. Jakarta: PT Raja Grafindo Persada.

Maggioli, G. D. (1996, April). The Good, the Bad and the Ugly. Learning Preferences in EFL. In English Teaching Forum (Vol. 34, No. 2, pp. 32-37).

Marwa, M. (2014). Reasons for Students' Code-Switching Between Informal Indonesian and English in ELT Contexts. ELT-Lectura, 1(1).

Mertler, C. (2012). Action research: Improving schools and empowering educators (3rd ed.). Thousand Oaks, CA: Sage.

Piasecka, L. (2014). Putting bits and pieces together: Awareness of text structure in jigsaw reading. In Awareness in Action (pp. 183-193). Springer, Cham.

Syafitri, Y. D. T., Budiarti, V., \& Derin, T. (2019). Reviewing the Effectiveness of Reading Aloud Technique in EFL Context: Is it Better than Silent 
Reading?. Lisan: Jurnal Bahasa dan Linguistik, 9(1), 37-43.

Tseng, M. C. (2008). The difficulties that EFL learners have with reading text on the web. Internet TESL Journal, 14(2).

Woo, M., Chu, S. K. W., Ho, A., \& Li, X. (2011). Using a wiki to scaffold primary-school students' collaborative writing. Educational technology \& society, 14(1), 43-54.

Yang, S. C. (2001). Language learning on the World Wide Web: An investigation of EFL learners' attitudes and perceptions. Journal of Educational Computing Research, 24(2), 155-181.

Yunira, S., Pradina, S., Sumbayak, M., Putri, N. S., \& Derin, T. (2019). Re-Visits the Grand Theory of Geoffrey Leech: Seven Types of Meaning. REiLA: Journal of Research and Innovation in Language, 1(3), 95-100. 